\title{
Erratum to: Platinum-based chemotherapy in triple-negative advanced breast cancer
}

\author{
Cynthia Villarreal-Garza ${ }^{1,2}$ - Daniel Khalaf ${ }^{3}$. Nathaniel Bouganim ${ }^{3}$. \\ Mark Clemons $^{3}$ - Omar Peña-Curiel ${ }^{1}$ - Berenice Baez-Revueltas ${ }^{4} \cdot$ Alexander Kiss $^{2}$. \\ Farah Kassam $^{5}$ - Katherine Enright ${ }^{5}$. Sunil Verma ${ }^{2}$ - Kathleen Pritchard ${ }^{2}$. \\ Jeff Myers $^{6} \cdot$ Rebecca Dent ${ }^{2,7}$
}

Published online: 26 March 2015

(C) Springer Science+Business Media New York 2015

\section{Erratum to: Breast Cancer Res Treat (2014) 146:567-572 \\ DOI 10.1007/s10549-014-3033-4}

In the above mentioned article, Fig. 1 was published erroneously which actually belongs to another analysis. The data described in the abstract and results are correct. The correct Fig. 1 is given in this erratum.

The online version of the original article can be found under doi:10.1007/s10549-014-3033-4.

\section{Rebecca Dent}

rebecca.dent@duke-nus.edu.sg

1 Instituto Nacional de Cancerología, Ciudad de México, Mexico

2 Sunnybrook Odette Cancer Centre, Toronto, Canada

3 Division of Medical Oncology, The Ottawa Hospital Cancer Centre and University of Ottawa, Ottawa, Canada

4 Instituto Tecnológico Autónomo de México, Ciudad de México, Mexico

5 Princess Margaret Hospital, Toronto, Canada

6 Trillium Health Partners Peel Regional Cancer Centre, Mississauga, Canada

7 National Cancer Center Singapore, Duke-NUS, Singapore, Singapore

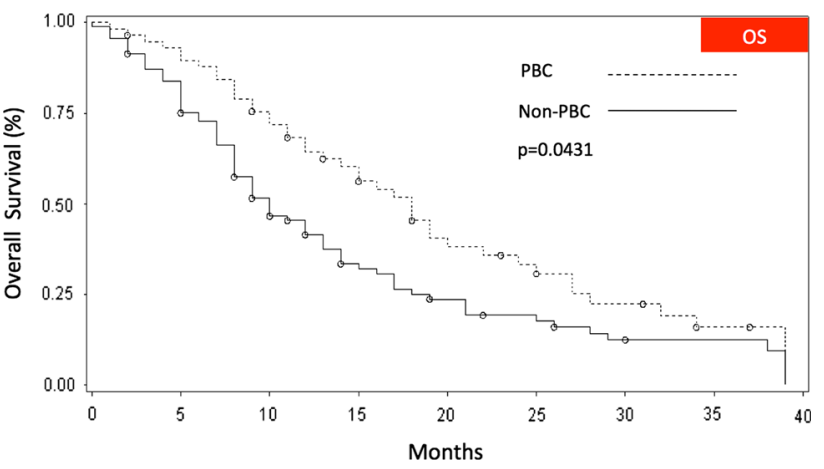

Fig. 1 Overall survival from time of distant metastatic disease to death or last follow-up 